Portland State University

PDXScholar

Physics Faculty Publications and Presentations

Physics

$12-1-2004$

\title{
Vertical Nanowire Light-Emitting Diode
}

Rolf Könenkamp

Portland State University, rkoe@pdx.edu

Robert Campbell Word

Portland State University

C. Schlegel

Portland State University

Follow this and additional works at: https://pdxscholar.library.pdx.edu/phy_fac

Part of the Physics Commons

Let us know how access to this document benefits you.

\section{Citation Details}

Könenkamp, R. R., Word, R. C., \& Schlegel, C. C. (2004). Vertical nanowire light-emitting diode. Applied Physics Letters, 85(24), 6004-6006.

This Article is brought to you for free and open access. It has been accepted for inclusion in Physics Faculty Publications and Presentations by an authorized administrator of PDXScholar. Please contact us if we can make this document more accessible: pdxscholar@pdx.edu. 


\title{
Vertical nanowire light-emitting diode
}

\author{
R. Könenkamp, ${ }^{\text {a) }}$ Robert C. Word, and C. Schlegel \\ Physics Department, Portland State University, 1719 SW 10th Avenue, Portland, Oregon 97201
}

(Received 29 March 2004; accepted 20 October 2004)

\begin{abstract}
We report room-temperature, white-color electroluminescence in vertically oriented $\mathrm{ZnO}$ nanowires. Excitonic luminescence around $380 \mathrm{~nm}$ is observed as a shoulder on a broader defect-related band covering all of the visible range and centered at $620 \mathrm{~nm}$. The $\mathrm{ZnO}$ nanowires are grown in a low-temperature process on $\mathrm{SnO}_{2}$-coated glass substrates, employing a technique that is suitable for large-area applications. The nanowires are robustly encapsulated in a thin polystyrene film deposited from high-molecular-weight solutions. Electron injection occurs through the transparent $\mathrm{SnO}_{2}$ layer, while hole injection is mediated by a $p$-doped polymer and an evaporated Au contact. Stable device operation is observed at ambient conditions on the time scale of 1 h. (C) 2004 American Institute of Physics. [DOI: 10.1063/1.1836873]
\end{abstract}

Low-dimensional semiconductor nanostructures, such as quantum wires and quantum dots, are promising for use as the active material in various optoelectronic devices because of their extremely small volume and modified light-matter interaction. ${ }^{1-5}$ Free-standing vertically arranged $\mathrm{ZnO}$ nanowires can be made in a variety of processes, including chemical vapor deposition, ${ }^{6}$ metalorganic vapor phase epitaxy, ${ }^{7}$ and electrodeposition. ${ }^{8,9}$ The latter is a low-temperature process compatible with glass and polymer substrates and produces crystalline nanowires of excellent electronic quality. ${ }^{9}$ The alignment of these nanowires produces unusual polarization effects ${ }^{10}$ and makes them of considerable interest in optical applications. A strong excitonic photoluminescence (PL) at $384 \mathrm{~nm}$ and a defect luminescence band around 600 $\mathrm{nm}$ is observed at room temperature. ${ }^{6,11}$ Here, we report on free-standing $\mathrm{ZnO}$ nanowires grown on transparent $\mathrm{SnO}_{2}$-coated glass substrates and embedded in a thin polystyrene (PS) film showing strong electroluminescence (EL) at room temperature. Without further encapsulation their operation as light-emitting diodes (LEDs) is stable for $\sim 1 \mathrm{~h}$ in ambient atmosphere.

$\mathrm{ZnO}$ nanowires were grown in electrodeposition from aqueous solutions on fluorine-doped $\mathrm{SnO}_{2}$-coated glass substrates of $5 \mathrm{~cm} \times 5 \mathrm{~cm}$ in size. The deposition involved a standard three-electrode arrangement with a Pt counter and reference electrodes. An aqueous solution of $5 \times 10^{-4} \mathrm{M}$ $\mathrm{ZnCl}_{2}$ and $0.1 \mathrm{M} \mathrm{KCl}$ was used, the $\mathrm{KCl}$ solution serving as a supporting electrolyte. The electrodeposition was carried out in the range from -660 to $-760 \mathrm{mV}$ versus the normal hydrogen reference electrode potential at $80{ }^{\circ} \mathrm{C}$ under externally induced convection and oxygen bubbling. Typical deposition currents were $0.6-1 \mathrm{~mA} / \mathrm{cm}^{2}$ after the nucleation process. ${ }^{12}$ The $\mathrm{ZnO}$ formation proceeds in two chemical steps. First, oxygen is electroreduced at the substrate surface. This increases the $\mathrm{OH}^{-}$-concentration at the surface, thereby leading to a second chemical reaction, the deposition of amorphous $\mathrm{Zn}(\mathrm{OH})_{2}$ or of crystalline $\mathrm{ZnO}$. Under appropriate conditions, which are detailed in Ref. 8, the latter material prevails and well-crystallized hexagonal $\mathrm{ZnO}$ columns of 100-200 nm diameter and up to $2 \mu \mathrm{m}$ in length can be grown. In electrodeposition, the $\mathrm{ZnO}$ growth proceeds under

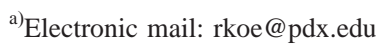

electron injection from the underlying $\mathrm{SnO}_{2}$ layer. It can therefore be expected that a reasonable electron contact at the $\mathrm{SnO}_{2} / \mathrm{ZnO}$ interface is established. Doping of the growing $\mathrm{ZnO}$ with $\mathrm{Al}$ can be performed by adding $1 \times 10^{-6} \mathrm{M}$ $\mathrm{AlCl}_{3}$ to the solution. ${ }^{9}$ In previous work, we carried out an electrical $^{9}$ and structural characterization of these nanowires. $^{12,13}$ The carrier mobilities in these nanowires match those on high-quality polycrystalline $\mathrm{ZnO}$ films. Typically, we find electron mobilities of the order of $10 \mathrm{~cm}^{2} / \mathrm{V} \mathrm{s}$ in undoped material, and slightly lower values in Al-doped films. ${ }^{9}$ Depending on the details of the deposition, the orientation of the wires can be optimized to be preferentially vertical to the substrate. ${ }^{12}$ The wires can be processed in a variety of ways, including coating, ion exchange, ${ }^{12}$ and etching. ${ }^{13}$ Figure 1 shows these single-crystalline wires and a cross-sectional view of a single wire. As illustrated in Fig. 2, for LED applications, a high-quality insulation of the $\mathrm{SnO}_{2}$ layer and a homogeneous filling of the space between them is desired, while only an extremely thin insulator layer on the wire tips can be afforded. We have approached this problem by using solution deposition of high-molecular-weight polymers, such as polystyrene, polyvinylene, and others. We followed recent work of Yan et al. ${ }^{14}$ who demonstrated that polymers adhere well to oxidic surfaces, when polymerization is supported by a short UV-curing process. The thick-

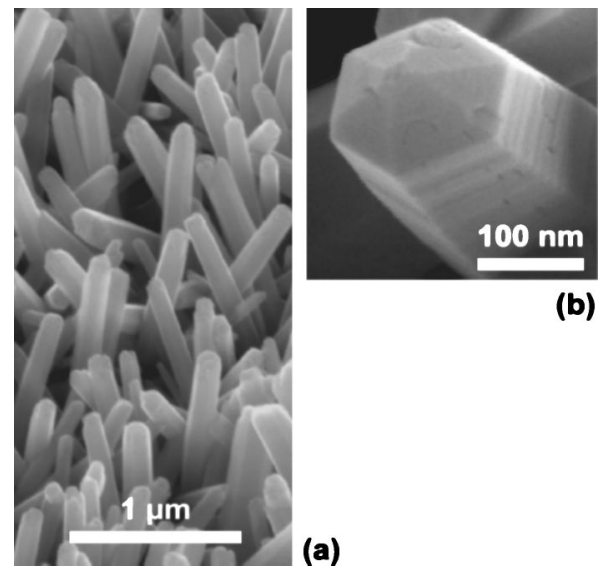

FIG. 1. (a) Electron micrograph of electrodeposited $\mathrm{ZnO}$ nanowires on polycrystalline $\mathrm{SnO}_{2}$ films on glass. (b) Tip view of a single $\mathrm{ZnO}$ wire showing a faceted hexagonal cross section. 


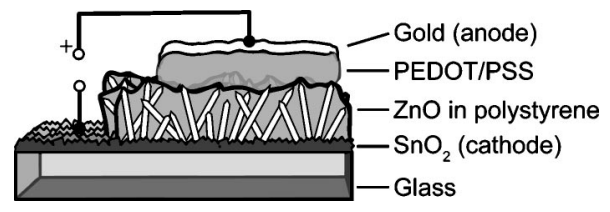

FIG. 2. Schematic diagram of nanowire LED arrangement with insulator filling the space between wires and a very thin film covering the wire tips.

ness of the polymer can be varied by adjusting the spin speed, the polymer molecular weight, and the polymer concentration. For the samples discussed here, we used a spin speed of $3000 \mathrm{rpm}$ and ps of molecular weight 1.7 $\times 10^{6} \mathrm{~g} / \mathrm{mol}$ in a concentration of $50 \mathrm{~g} / \mathrm{L}$ dissolved in toluene. The films were UV cured for $30 \mathrm{~min}$, soaked in toluene for $10 \mathrm{~min}$, and rinsed by pipette with $3 \mathrm{~mL}$ toluene. Figure 3 shows electron micrographs of the obtained films. Figure 3(c) shows that a very thin coating on top of the nanowires can be achieved, while the space between wires is solidly filled with the polymer. From the electron micrograph, we estimate the ps layer thickness on the nanowire tips to be in the range of $10-50 \mathrm{~nm}$. This thickness is comparable to the thickness obtained on planar substrates using similar experimental conditions, i.e., spin speed, molecular weight, etc., as used here. ${ }^{14}$ At this thickness, the ps is only a weak insulator; current transport occurs through electronic and structural defects and due to dielectric breakdown. To establish a $p$-type contact to the nanowire tips, we applied a coating of poly(3,4-ethylene-dioxythiophene)(PEDOT)/poly(styrenesulfonate) on top of the ps layer. The solution layer was deposited manually in a paint-brush process, which establishes a better homogeneity than spin coating and results in a layer thickness of approximately $0.5-1.5 \mu \mathrm{m}$. Within this thickness range, no qualitative changes in the device behavior was observed. Finally, a $100 \mathrm{~nm}$ thick Au layer was deposited by vacuum evaporation to provide a Schottky barriertype contact for hole injection. ${ }^{15}$

Figure 4 shows the electrical and optical device characteristics of the obtained LEDs. After some forming action which is likely to occur in the polymer layers at high electrical fields and which results in a steady reduction of the conductance across the device, the current-voltage $(I-V)$ characteristics become diodelike. In fast voltage scans, $>10 \mathrm{~V} / \mathrm{s}$, negative differential resistance (NDR) is observed over a limited voltage range. We attribute this behavior to charging in a defect-controlled transport process through the residual PS layer at the nanowire tips. In slower voltage scans, the NDR disappears and monotonic rectifying behavior prevails. Visible emission of white light sets in at current densities of $5 \mathrm{~mA} / \mathrm{cm}^{2}$, corresponding to $\sim 100 \mathrm{~mA} / \mathrm{cm}^{2}$ at the nanowire tip. Figure 4(b) compares the PL and EL spectra of our $\mathrm{ZnO}$ nanowires. The EL spectrum comprises a broad defect-related distribution centered at $620 \mathrm{~nm}$. This distribution covers most of the visible spectrum and gives rise to the apparent white color of the emission. There is a distinct shoulder extending into the UV region down to wavelengths of $360 \mathrm{~nm}$, which is clear evidence of an additional and sizeable excitonic contribution. ${ }^{7,16}$ In the PL spectrum of uncoated nanowires, the excitonic contribution is much more pronounced. More detailed work showed that the relative strength of the UV and visible bands is somewhat dependent on the substrate properties and processing details. ${ }^{11}$ The comparably low UV contribution in the EL
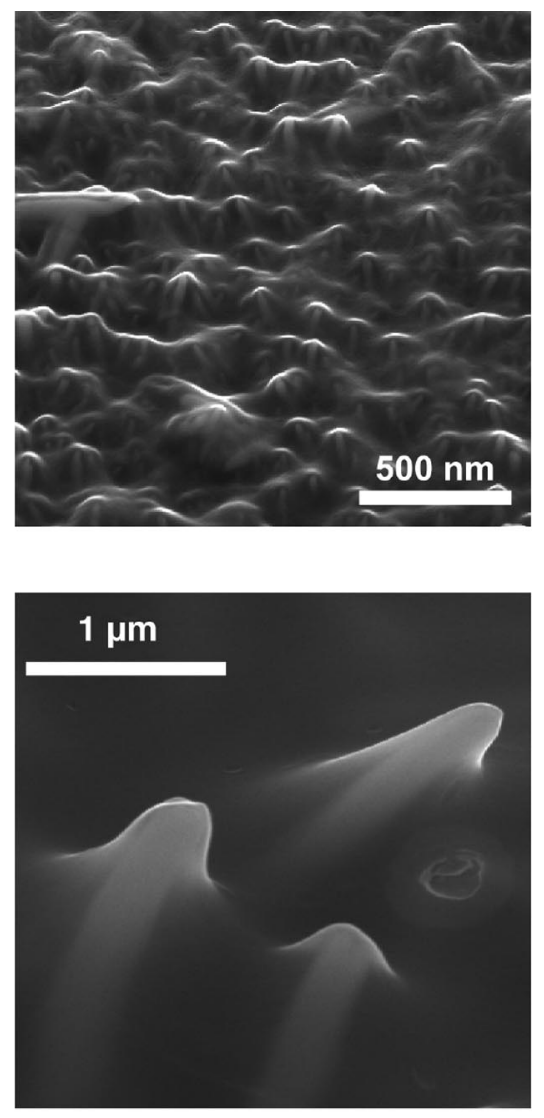

(b)

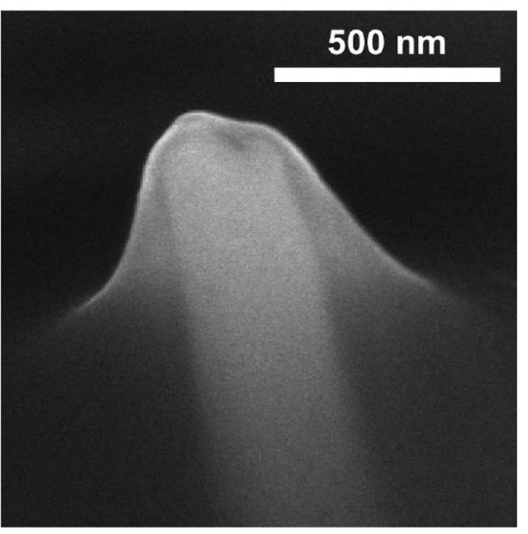

FIG. 3. Electron micrograph of nanowires embedded in PS. (a) Overview at $\sim 45^{\circ}$ beam incidence. (b) Close-up of nanowire tips with PS showing thin PS coverage at nanowire tips. (c) Scanning electron micrograph of a single nanowire tip. The layer thickness ranges between $\sim 10$ and $50 \mathrm{~nm}$ depending on preparation conditions.

may be due to a slow and trap-influenced transport process that leads to a stronger reduction of the average carrier energy in EL than in the homogeneously excited PL. Alternatively, the $\mathrm{ZnO}$ /polymer interface may produce a stronger defect luminescence than the interface to air. We expect that more work can clarify these issues and will soon lead to an increase the UV portion of the EL.

From the known values of band gap, work function, dopability, and on the basis of the observed $I-V$ and luminescence characteristics, we conclude that the $\mathrm{SnO}_{2} / \mathrm{ZnO}$ interface provides comparably good electron transfer. This idea is also supported by the fact that the electrodeposition process occurs under electron transfer. Since the hole-injecting contact at the nanowire tips has a residual PS interface layer 


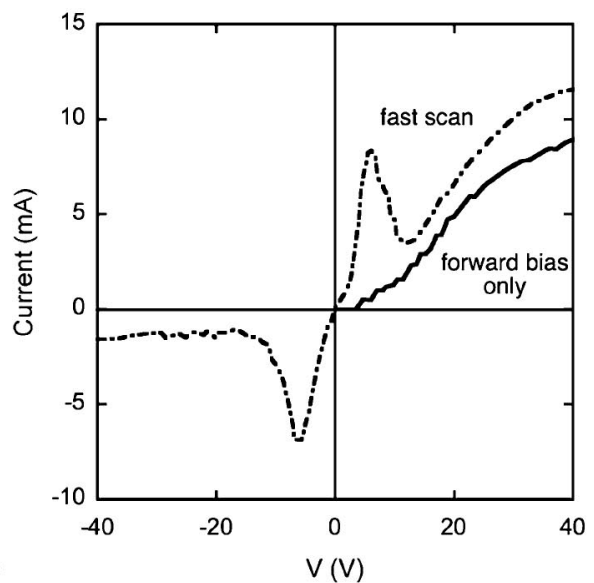

(a)

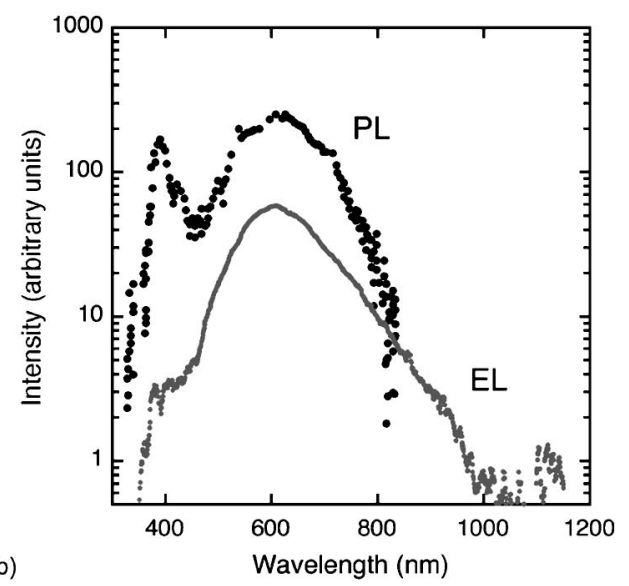

FIG. 4. (a) $I-V$ characteristics of the LED structure. For fast scans a NDR regime is observed, that can be attributed to a slow transport process and charging. In slower scans, a monotonic behavior is found. (b) PL and EL spectra obtained at room temperature in air. The PL is obtained with excitation at $355 \mathrm{~nm}$ of a frequency-tripled Nd-YAG laser. A strong excitonic band at $384 \mathrm{~nm}$ and a defect-related band centered at $620 \mathrm{~nm}$ are observed. The EL occurs at a threshold of $\sim 10 \mathrm{~V}$. As in the PL spectrum, a defectrelated band centered at $620 \mathrm{~nm}$ is observed. A shoulder indicates excitonic luminescence in the UV region.

between the nanowires and the PEDOT/Au layer, we expect the injection of holes through this contact to be the performance-limiting process in the present device configuration. Future work will have to address further reduction of the PS thickness at the nanowire tips.

In Fig. 5, we show stability data for the device operation under ambient air at room-temperature conditions and without encapsulation. In EL operation, we observe stability over time periods of typically $1 \mathrm{~h}$. After this time, a gradual decrease in current density accompanied by a decrease in brightness is observed. To a good approximation, the decay dependence follows a stretched exponential behavior, $I(t)$ $=I_{o} \exp \left(-(t / \tau)^{\alpha}\right)$ with $\tau=7000 \mathrm{~s}$ and $\alpha=0.7$. As the nanowires are not completely uniform in dimensions, alignment, and contact area, a distribution in $\tau$ may be expected, explaining qualitatively the stretched exponential behavior. ${ }^{17}$

To conclude, we have observed EL in vertically oriented $\mathrm{ZnO}$ nanowires at room temperature. The EL spectrum ranges from $360 \mathrm{~nm}$ throughout the visible spectrum. A comparison with the PL spectrum indicates that excitonic and defect transitions are involved. It can be expected that further work will achieve an enhancement of the excitonic transi-

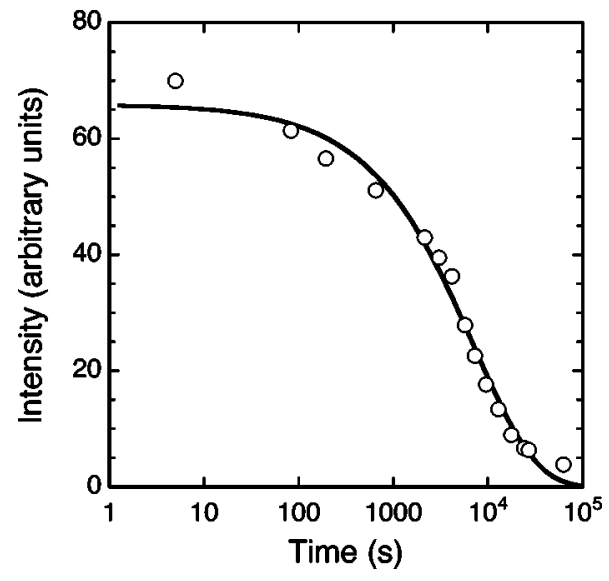

FIG. 5. Stability of light emission at room temperature in air. The solid line is a least-squares fit based on a stretched exponential dependence, $I(t)$ $=I_{o} \exp \left(-(t / \tau)^{\alpha}\right)$ with $\tau=7000 \mathrm{~s}$ and $\alpha=0.7$.

tions, and that blue or UV LEDs can eventually be developed. In the present configuration, the nanowires are embedded in a transparent polymer. This configuration is mechanically very robust. The near-vertical orientation allows one to use sandwich-like contacts, which can easily be patterned. Although not shown here, it can be expected that light emission and polarization will be affected by the directional orientation of the nanowires. ${ }^{18}$ It appears feasible to lift the nanowire film off the substrates and, by this route, obtain a robust flexible LED arrangement with inorganic active components. First experiments show stable operation in ambient conditions for $\sim 1 \mathrm{~h}$.

It is a pleasure to acknowledge experimental support in the polymer deposition process by Professor M. Yan and B. Harnish at Portland State University.

${ }^{1}$ E. Kapon, Semiconductor Lasers (Academic, San Diego, 1998), Vol. 1, Chap. 4.

${ }^{2}$ M. Grundmann, Physica E (Amsterdam) 5, 167 (2000).

${ }^{3}$ W. I. Park, D. H. Kim, S. W. Jung, and G.-C. Yi, Appl. Phys. Lett. 80, 4232 (2002).

${ }^{4}$ J. Wang, M. S. Gudiksen, X. Duan, Y. Cui, and C. M. Lieber, Science 293, 1456 (2001).

${ }^{5}$ H. Weman, L. Sirigu, K. F. Karlsson, K. Leifer, A. Rudra, and E. Kapon, Appl. Phys. Lett. 81, 2839 (2002).

${ }^{6}$ B. Y. Geng, T. Xie, T., X. S. Peng, Y. Lin, X. Y. Yuan, G. W. Meng, and L. D. Zhang, Appl. Phys. A: Mater. Sci. Process. 77, 363 (2003).

${ }^{7}$ W. I. Park, Y. H. Jun, S. W. Jung, and G.-C. Yi, Appl. Phys. Lett. 82, 964 (2003).

${ }^{8}$ S. Peulon and D. Lincot, J. Electrochem. Soc. 145, 864 (1998).

${ }^{9}$ R. Könenkamp, K. Boedecker, M. C. Lux-Steiner, M. Poschenrieder, F. Zenia, and C. Leavy-Clement, Appl. Phys. Lett. 77, 2575 (2000).

${ }^{10}$ Y. Du. S. Han, W. Jin, C. Zhou, and A. F. Levi, Appl. Phys. Lett. 83, 996 (2003).

${ }^{11} \mathrm{R}$. Könenkamp (unpublished).

${ }^{12}$ L. Dloczik, R. Engelhardt, K. Ernst, M. C. Lux-Steiner, and R. Könenkamp, Sens. Actuators B 84, 33 (2002).

${ }^{13}$ L. Dloczik, R. Engelhardt, K. Ernst, S. Fiechter, I. Sieber, and R. Könenkamp, Appl. Phys. Lett. 78, 3687 (2001).

${ }^{14}$ M. Barlett and M. Yan, Polym. Mater. Sci. Eng. 83, 451 (2000).

${ }^{15}$ W. I. Park and G.-C. Yia, J.-W. Kim, and S.-M. Park, Appl. Phys. Lett. 82, 4358 (2003).

${ }^{16}$ D. M. Bagnall, Y. F. Chen, Z. Zhu, T. Yao, S. Koyama, M. Y. Shen, and T. Goto, Appl. Phys. Lett. 70, 2230 (1997).

${ }^{17}$ R. MacDonald, J. Appl. Phys. 82, 3962 (1997).

${ }^{18}$ Y. Du, S. Han, W. Jin, C. Zhou, and A. F. J. Levi, Appl. Phys. Lett. 83, 996 (2003). 
Applied Physics Letters is copyrighted by the American Institute of Physics (AIP). Redistribution of journal material is subject to the AIP online journal license and/or AIP copyright. For more information, see http://ojps.aip.org/aplo/aplcr.jsp 